\title{
The effectiveness of simulation in advancing quality and safety education for nurses-based competency in accelerated nursing students
}

\author{
Samira Moughrabi, Debra R. Wallace * \\ School of Nursing, California State University of Northridge, Northridge, United States
}

Received: March 23, 2015

Accepted: May 11, 2015

Online Published: May 13, 2015

DOI: $10.5430 /$ jnep.v5n8p17

URL: http://dx.doi.org/10.5430/jnep.v5n8p17

\begin{abstract}
Newly licensed Registered Nurses (RNs) have an obligation to be safe and effective in their first job. The transition of nursing graduates to the new RN role should ensure the key components of safety and effectiveness are present. Transitions can be made more effective through the use of simulations. Rubrics can be used in simulations to help validate progression in learning from simple to more complex care concepts. A study was conducted to assess the effectiveness of the use of simulations utilizing rubrics to assess progression in performance in second degree students enrolled in an accelerated nursing program. Findings indicate that the use of simulation, utilizing Quality and Safety Education for Nurses (QSEN)-based rubrics for assessment, can improve competence in patient care and safety, thus contributing to a successful transition to practice.
\end{abstract}

Key Words: Simulation, Assessing competence, Nursing education, Rubrics

\section{INTRODUCTION}

Healthcare related errors have been the leading cause of death and injury in the United States. They are responsible for as many as 220,000 to 440,000 preventable adverse deaths and 6.1 million injuries each year, with a social cost ranging from $\$ 393$ billion to $\$ 958$ billion. ${ }^{[1,2]}$ Thus, it is imperative that nursing education programs prepare graduate nurses who are capable of providing safe and effective nursing care to their patients. Nevertheless, this task may be challenging to the majority of nursing programs given the increased acuity of hospitalized patients, accelerated nature of nursing program for second degree students, and the competitiveness in accessing patient care facilities to train nursing students. Simulation has been proposed as a valuable solution to overcome these challenges and thus has increasingly been utilized by nursing programs as an alternative to meet and supplement clinical training requirements in nursing education.

Simulation is a training and feedback strategy where one learns to develop and apply the knowledge and skills to create lifelike circumstances of the real world and receive feedback to assist in improving and refining to meet educational needs. ${ }^{[3]}$ Simulation engages student in learning and can be designed to increase students' learning activities independent of faculty. Likewise, simulation can foster a high level of student responsibility in a scenario; something that may not be possible in a traditional clinical setting. ${ }^{[4-6]}$ The transition from carefully controlled educational experiences to a fast paced clinical world of increasing patient complexity requires a strong sense of self confidence, critical thinking, clinical reasoning, and teamwork. Novice regis-

\footnotetext{
*Correspondence: Debra R. Wallace; Email: debra.wallace@ csun.edu; Address: School of Nursing, California State University of Northridge, Northridge, United States.
} 
tered nurse (RN) graduates must be competent, safe, and efficient in their first job. Within weeks of graduation, they can enter clinical settings where they are expected to assume professional responsibilities and take on patient care assignments. However, there is evidence to suggest that some of these RNs have reported feeling unprepared for the transition to the $\mathrm{RN}$ role. ${ }^{[7]}$ Accordingly, the Institute of Medicine (IOM) affirms that academic programs should utilize the use of simulation for teaching novice healthcare practitioners the knowledge and skills needed, especially when introducing new and potentially hazardous procedures and equipment. ${ }^{[3]}$

\subsection{Specific aims}

The aim of this study was to examine, using Quality and Safety Education for Nurses (QSEN)-based rubrics the efficacy of simulation in advancing education and competency in medical surgical nursing among students enrolled in an accelerated baccalaureate program at a state university in California.

\subsection{Literature review}

Access to technology for simulation is easier than ever before with the opening of several simulation centers throughout the world $^{[8]}$ and the increasing availability of more sophisticated and affordable patient simulators. Although the majority of research regarding the utilization of patient simulators has been performed in medical settings showing they are educationally effective, similar studies are limited in nursing and thus, there is a need for additional evidence that supports the use of this technology in nursing education. ${ }^{[9]}$

The versatility and adaptability of patient simulators allow for teaching junior nursing students basic assessment and psychomotor skills, evolving to more complex clinical scenarios as students advance in their program. Research concerning the use of a patient simulator may broaden and deepen the challenges and direct the development of opportunities for new graduate nurses. The use of simulation as a practical educational method is becoming more common, using fullscale, realistic, medical simulation for training healthcare professionals. ${ }^{[10]}$ They allow for demonstrating procedures, along with promoting decision making and critical thinking skills. ${ }^{[11,12]}$ Simulations utilize essential experiences and encounters with specific populations and allows active student participation and learning. Simulations also allow faculty to center their attention on the students' training and performance, rather than focus on protecting the patient from possible student error. This allows educators to provide real-time feedback to students to refine techniques. ${ }^{[13,14]}$ Although full implementation of simulations is a growing strategy to enhance clinical practice education, full implementation re- quires a broader scope than dependence on manikin-based simulations alone.

\subsection{Rubrics: Tools to assess performance}

Rubrics are identified as scoring tools, which specify expectations required for successful performance. ${ }^{[15]}$ They help ensure successful transitions to practice and provide an objective measure of success. ${ }^{[3]}$ Wallace and Boller (2014) state that rubrics clarify performance expectations, direct student focus, define clear expectations, incorporate formative and summative assessment, and identify the next steps in education. ${ }^{[16]}$ The Robert Wood Johnson Foundation funded an initiative to establish rubrics congruent with the QSEN competencies to explore the complexity of competent performance. As an outgrowth of improving patient care safety by redefining health care educational systems, a team of nurse educators from across the country ${ }^{[17]}$ developed a framework for educating nurses called Quality and Safety Education in Nursing. QSEN ensures that future nurses will continuously participate in optimizing the quality and safety of healthcare systems. ${ }^{[1,18]}$ Interests were centered in areas focusing upon patient-centered care, evidence-based practice, teamwork and collaboration, safety, quality improvement, and informatics at both basic and graduate levels of practice. ${ }^{[19]}$ Our Nursing department has committed to embedding the QSEN-based activities throughout the curriculum. To help us meet the challenge of introducing a new framework we developed a tool for evaluating student performance during the simulation using the QSEN framework (see Table 1). Since many of our clinical agency partners use QSEN in staff development, we anticipate that QSEN based tools such as this one may give us an indication of our graduates' readiness for new graduate training. The goal was that the rubric will facilitate assessment of students' clinical judgment following simulation learning activities by recognizing and understanding relationships and patterns in the various QSEN competencies.

\subsection{Theoretical framework}

\subsubsection{The novice-to-expert model for developing compe- tency skills}

Patricia Benner introduced the novice-to-expert model (1984), which conceptualized the framework for understanding skills acquisition by delivering a comprehensive and holistic framework. ${ }^{[20]}$ She identified five qualitatively different levels of perception and performance that nurses may progress through over time: novice, advanced beginner, competent, proficient, and expert. The level of competency representing movement from novice to expert can be evaluated using rubrics beyond the transition-to-practice phase. ${ }^{[21]}$ 
Table 1. Simulation grading rubric

\section{Simulation Grading Rubric}

ASSESSMENT AND CRITICAL THINKING
Concise 10 minute initial and focused problem assessment
Hand hygiene: Uses proper hand hygiene before caring for the patient and as needed.
Introduces self with first, last name and role (nursing student) to patient, family
member and/or health care provider.
Patient identification: Checks patient's name, DOB, medical number to make sure
that the ID band is present and correct. Look at band and ask patient to state their name
and DOB.
Allergy band: Asks the patient if has any allergies AND check the correct allergy
band.
ABCs and LOC: Assesses ABCs patient's Airway (able to speak), Breathing (chest
rising and falling), Circulation (check pulses) and Level of Consciousness (should
state out loud assessing these areas).

Vital signs $/ \mathrm{O}_{2}$ Sat/Pain: Assesses initial and previous vital signs $/ \mathrm{O}_{2}$ Sat/pain by comparing to previous vital signs $/ \mathrm{O}_{2}$ Sat/pain and identifies normal and/or abnormal as scenario evolves

Communication: As appropriate explains to patient/and or family member what you are doing and/or why.

Check Tubes and Equipment: Check tubes and equipment from their source to their connection with the patient. For example: Check IV for proper solution, rate, air, connected, and IV site for patency and erythema.

Focus Assessment based on patient presentation and complaints-assesses systems appropriately. Signs and symptoms.

For example: heart, lungs, abdomen, extremities, and skin integrity

\section{PROBLEM IDENTIFICATION CRITICAL THINKING}

Problems: Identifies at least 1 actual and/or possible nursing problem for the patient (Can identify while thinking out loud).

\section{INTERVENTIONS, EVALUATION AND CRITICAL THINKING}

Error: Able to identify at least 1 possible medical error and interrupts error.

Priority interventions: Initiates appropriate priority interventions for the patient in a timely manner.

Communicates with MD to implement interventions in a timely manner. Gives appropriate information using SBAR guidelines (see sheet need the phone to call physician if needed)

\section{COGNITIVE DEVELOPMENT}

Thinking Process: Thinks out loud during or after the scenario about what are the possible problems, pathophysiology, and/or rationale for assessment and interventions.

Reflection: Able to identify strengths and areas of improvement when viewing video with objectives and discussion with instructor and peers

\section{Total:}

Grade:

\begin{tabular}{|c|c|c|}
\hline $\begin{array}{l}\text { PATIENT with } \\
\text { Atypical Chest Pain } \\
\end{array}$ & $\begin{array}{l}\text { Possible } \\
\text { Points }\end{array}$ & $\begin{array}{l}\text { Actual } \\
\text { Points }\end{array}$ \\
\hline _Hand wash & 2 & \\
\hline $\begin{array}{r}\text { Identifies self } \\
\text { Identifies role }\end{array}$ & 2 & \\
\hline $\begin{array}{l}\text { Ask Patient Full Name } \\
\text { Ask Patient DOB } \\
\text { Checks MR\# }\end{array}$ & 2 & \\
\hline $\begin{array}{l}\text { Asks patient about allergies } \\
\text { Check for allergy band }\end{array}$ & 2 & \\
\hline $\begin{array}{l}\text { Airway } \\
\text { Breathing (check) } \\
\text { Circulation (check pulses) } \\
\text { LOC (ask questions) }\end{array}$ & $\begin{array}{l}4(1 \text { point } \\
\text { each) }\end{array}$ & \\
\hline 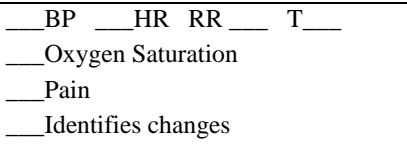 & $\begin{array}{l}7 \text { ( } 1 \text { point } \\
\text { each) }\end{array}$ & \\
\hline $\begin{array}{l}\text { Explain Assessment } \\
\text { Explain Interventions }\end{array}$ & $\begin{array}{l}5 \text { ( } 2.5 \text { points } \\
\text { each) }\end{array}$ & \\
\hline __ Saline lock & 5 & \\
\hline $\begin{array}{l}\text { Chest Pain Assessment } \\
\text { When started } \\
\text { Location? _ Radiation? } \\
\text { Quality? Pain } \\
\text { Depressed ST segment } \\
\text { O2 Sat lower }\end{array}$ & $\begin{array}{l}5 \text { (1 point } \\
\text { each) }\end{array}$ & \\
\hline $\begin{array}{l}\text { Unstable Angina } \\
\text { Allergy to shellfish-problem with } \\
\text { order for Cardiac Cath with contrast }\end{array}$ & $\begin{array}{l}5 \text { ( } 2.5 \text { points } \\
\text { each) }\end{array}$ & \\
\hline ___ Allergy bracelet off & $\begin{array}{l}5 \text { ( } 2.5 \text { points } \\
\text { each) }\end{array}$ & \\
\hline $\begin{array}{l}\text { Raise HOB } \\
\text { Apply oxygen } \\
\text { Get EKG } \\
\text { Give NTG } \\
\text { Assesses VS before each NTG } \\
\text { Calls MD } \\
\begin{array}{l}\text { After call to MD do or say what would } \\
\text { do: }\end{array} \\
\text { Increase O2 _ ASA } \\
\text { Morphine }\end{array}$ & $\begin{array}{l}5 \text { ( } 0.5 \text { points } \\
\text { each) }\end{array}$ & \\
\hline $\begin{array}{ll}\text { Situation } \quad \text { Background } \\
\text { Assessment } \\
\text { Recommendations } \\
\text { Read Back }\end{array}$ & $\begin{array}{l}5 \text { (1 point } \\
\text { each) }\end{array}$ & \\
\hline __ Rationale(s) for actions & 10 & \\
\hline $\begin{array}{l}\text { Strengths } \\
\text { Areas to improve }\end{array}$ & $\begin{array}{l}10 \text { ( } 5 \text { points } \\
\text { each) }\end{array}$ & \\
\hline Comments: & $\begin{array}{l}72(54 \text { points } \\
=75 \%\end{array}$ & \\
\hline
\end{tabular}


Benner's concepts regarding the performance characteristics and learning needs of nursing students with varying levels of clinical competency were incorporated in this study. Studies have shown that with appropriate training and feedback, the path to expertise can be accelerated. ${ }^{[18]}$ Rubrics provide a guide to focus on key areas in skill development for both learners and their mentors, providing a method to document the progress.18As new RNs move from novice to expert, rubrics can provide a guide to focus on essential competencies at different levels of skill performance. ${ }^{[18]}$

The growing increase in the complexities in patient care for the novice RN nationally has led to a need to evaluate and identify themes to assist in facilitating the recruitment, transition, and retention of competent novice nurses into the nursing profession. The significance of this study, and its potential benefits and impact, will be of interest to both the healthcare facilities that hire future nurses and the educational institutions that prepare and train them. ${ }^{[18]}$

\section{Methodology}

\subsection{The simulation experience}

Evidenced Based Practice (EBP) simulations were developed in the first and second semesters of the accelerated BSN (ABSN) enrolled in Nursing Fundamentals and medical surgical courses and students were assigned EBP readings prior to the simulations. The simulation exercise was a part of an approved module with structured learning aims and outcomes. Students in their first and second semesters were required to participate in the simulation as a part of their preparation for the medical surgical rotation. Three clinical groups of nine to ten students each completed the simulation in each simulation session. For each simulation, students worked in groups of three and the scenarios ran three times per day. If students did not intervene appropriately, the patient's condition would sometimes become more challenging. ${ }^{[21]}$ The end of the simulation was determined by the clinical faculty, case conclusion, or expiration of the patient. Resources such as mock paperwork, electrocardiogram (ECG) and blood results were made available as requested. In addition, skills stations were set up for students to practice procedures in order to develop their levels of confidence. Each scenario took between 15 and 20 minutes, including a structured debrief for the participating team. Overall debriefing took place after all simulations were completed and included all participating students. During this debriefing, students were given the opportunity to describe their experiences and identify learning facilitators and challenges they encountered during their engagement in simulation.

After the simulations were completed, the QSEN-based Sim- ulation Evaluation Surveys were administered in a paper form to all student participants. The participants were invited to provide written comments by including blank space at the end of the surveys. To avoid coercion, participants were told that they could return blank surveys if they did not wish to participate in the study.

\subsection{Instruments}

The authors developed a checklist using the case flow description of learner actions that are expected to occur during the simulation. After categorizing the learner actions, we evaluated the following competencies using the QSEN-based Simulation Evaluation Survey (see Table 2): Patient Centered Care (PCC); Communication, Teamwork and Collaboration (T\&C); Evidence Based Practice (EBP); and Safety (S). The Simulation Evaluation Survey was developed from the synthesis of literature and was designed to assess the relevance of simulation and whether simulations helped students develop stronger cognitive and clinical competencies and skills. After a panel of content experts previewed the rubrics for relevance and clarity, face validity was established. Assessing content validity is indispensable to validating performance indicators and descriptors that are representative of the characteristics being measured.16 For consistency of measurement, one of the investigators (clinical faculty) rated all student performances according to the simulation grading rubric.

\subsection{Data analysis}

Data from the students' responses was coded and analyzed using the Statistical Package for Social Sciences (SPSS) for Mac version 19.0. The focus of the analysis consisted of a comparison of the levels of knowledge in clinical skills and procedures, critical thinking, prioritization of patient care, time management, problem solving, and communication. Student participants ranked items on a four point Likert scale of strongly agree (+4), agree (+3), disagree ( +2$)$, and strongly disagree $(+1)$, as well as complete short write-in items. A T-test was used to examine the differences between the fundamental course and the medical-surgical course students' evaluation scores on debriefing, critical thinking, preparation for clinical practice, application of learned knowledge and skills to clinical practice, confidence, team work, and professionalism. Significance was set at $\alpha \leq 0.05$.

With the intent of evaluation of the short write-in questions, the investigators conducted a single thematic analysis, using an empiric analysis technique to categorize the data for relevance to practice, areas for recommendations, and future use. Qualitative data was reported using percentages and frequencies of themes identified in the analysis. 
Table 2. Simulation evaluation rubric

\section{Simulation Evaluation Rubric \\ California State University, Northridge \\ Department of Nursing}

Date:

Course:

Cohort:

Please circle your answer according to the following:

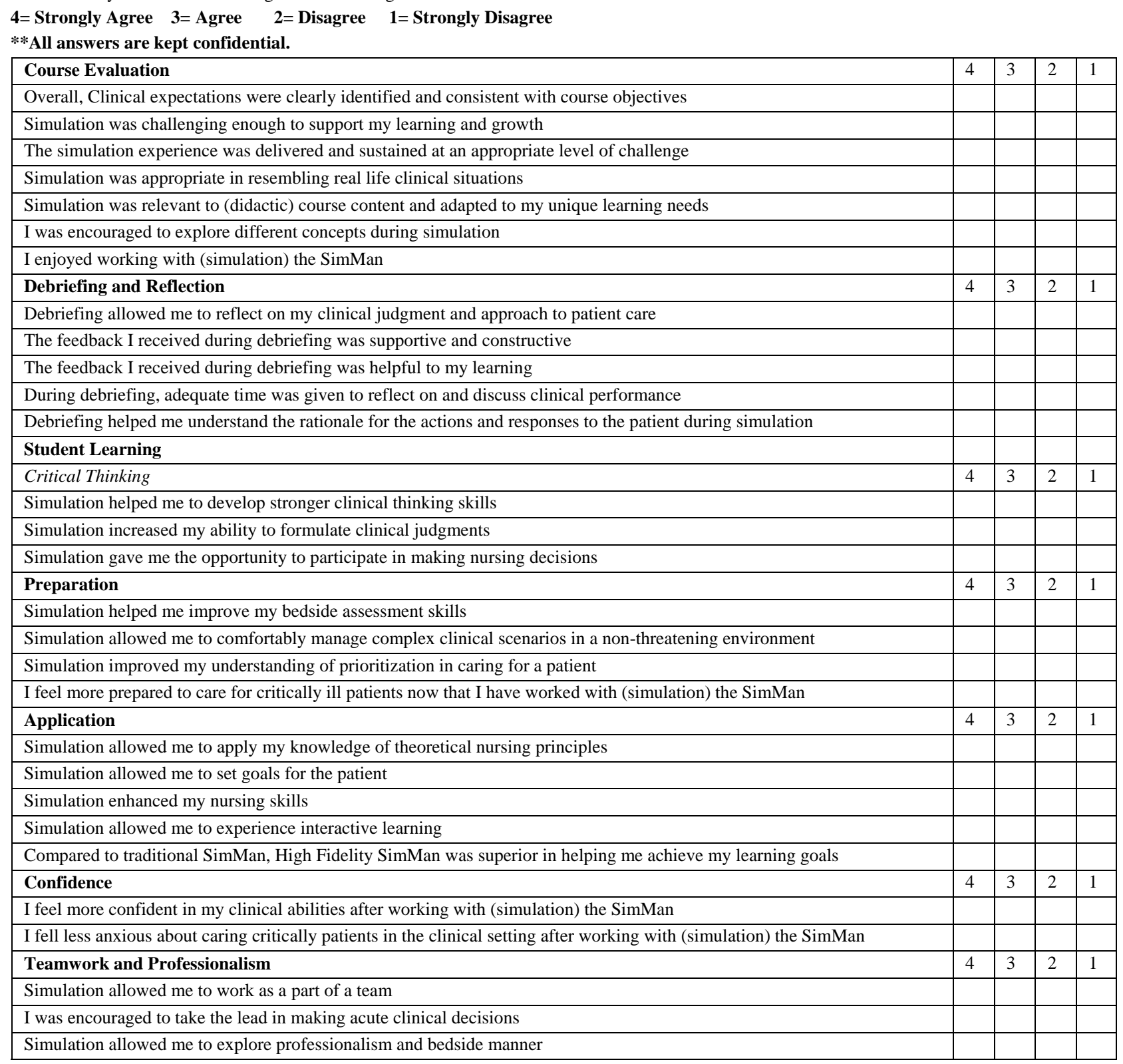

What did you like most about working with the SimMan?

If there is anything that you would change about your experience, what would that be?

\subsection{Ethical consideration}

The study was an end-of-the semester evaluation and data was a part of a module within the curriculum, and ethical

Published by Sciedu Press

approval was acquired from the Institutional Research Board (IRB) of the university. All questionnaires were anonymous to maintain confidentiality of the student participants. It 
was reinforced to all participants that their participation in completing the simulation evaluations was entirely voluntary and would not in any manner affect their performance evaluation and completion of the course. Students were also assured their answers would remain confidential since all data would be reported in aggregate and their names would not be included on the surveys.

\section{RESUlts}

\subsection{Comparison between nursing fundamentals course and medical-surgical course on study variables}

The scores of the Likert scale components comparing the study variables during simulation are presented in Table 3. Data analysis showed that simulation was effective in enhancing students learning in some, but not all, the clinical competency components we examined. Significance was noted in the change in overall expectations $(3.28 \pm 0.84 \mathrm{vs}$. $3.6 \pm 0.58, p=.005)$; prioritization $(3.34 \pm 0.65 v s .3 .62$ $\pm 0.60, p=.005)$; setting goals for patients $(3.08 \pm 0.67 v s$. $3.43 \pm 0.60, p=.002)$; confidence in clinical abilities $(3.23$ \pm 0.64 vs. $3.56 \pm 0.54, p=.00)$; and professionalism (3.34 \pm 0.67 vs. $3.82 \pm 0.42, p=.00)$. Among the components of "debriefing" evaluation, only debriefing feedback was significantly different between students taking both courses (3.44 \pm $.65 v s .3 .71 \pm 0.5, p=.004)$. Although the rating of debriefing time was not different between the two groups, a trend towards significance was observed $(3.32 \pm 0.67$ vs. $3.59 \pm$ $0.56, p=.007)$. Similarly, feeling prepared to care for critically ill patients showed a trend towards significance (3.13 \pm $0.77 v s .3 .33 \pm 0.63, p=.07)$. Students also felt that working with the high fidelity simulator was superior to traditional simulators, but it did not reach statistical significance (3.31 \pm 0.77 vs. $3.52 \pm 0.59, p=.06)$. Although students were working on simulation case scenarios in groups and alternating main responsibilities for "patient" care, it was interesting to find that the students did not feel that simulation was helpful in improving teamwork nor taking the lead in making acute clinical decisions. Simulation was also not found to be effective in improving the students' level of anxiety in caring for critically ill patients despite the improvement in the scores of clinical abilities.

Table 3. Comparison between nursing fundamentals course and medical-surgical course on study variables

\begin{tabular}{|c|c|c|c|c|c|c|c|}
\hline & \multirow{2}{*}{$\begin{array}{l}\text { mean } \pm \text { SD } \\
\text { Fundamental } \\
\mathrm{N}=72\end{array}$} & \multirow{2}{*}{$\begin{array}{l}\text { mean } \pm \text { SD } \\
\text { Med-surg } \\
\mathbf{N}=\mathbf{8 8}\end{array}$} & \multirow[t]{2}{*}{$t$} & \multirow{2}{*}{$\begin{array}{l}\text { Sig. } \\
\text { (2-tailed) }\end{array}$} & \multirow{2}{*}{$\begin{array}{l}\text { Mean } \\
\text { Difference }\end{array}$} & \multicolumn{2}{|c|}{$\begin{array}{l}95 \% \text { Confidence } \\
\text { Interval of the } \\
\text { Difference }\end{array}$} \\
\hline & & & & & & Lower & Upper \\
\hline Overall, clinical expectation & $3.28 \pm 0.84$ & $3.6 \pm 0.58$ & 2.878 & $.005^{*}$ & .324 & .102 & .547 \\
\hline Simulation challenging & $3.55 \pm 0.58$ & $3.6 \pm 0.56$ & .532 & .596 & .048 & -.131 & .228 \\
\hline Simulation resemble real life & $3.28 \pm 0.72$ & $3.14 \pm 0.75$ & -1.174 & .242 & -.138 & -.371 & .094 \\
\hline Relevance to didactic course & $3.40 \pm 0.66$ & $3.45 \pm 0.61$ & .501 & .617 & .051 & -.149 & .251 \\
\hline Enjoyed working with SimMan & $3.49 \pm 0.73$ & $3.31 \pm 0.68$ & -1.559 & .121 & -.176 & -.398 & .047 \\
\hline $\begin{array}{l}\text { Debriefing \& reflection on clinical judgment \&amp; patient } \\
\text { care }\end{array}$ & $3.47 \pm 0.56$ & $3.57 \pm 0.60$ & 1.037 & .301 & .096 & -.087 & .279 \\
\hline Debriefing feedback supportive\& amp; constructive & $3.44 \pm 0.67$ & $3.63 \pm 0.59$ & 1.944 & .054 & .196 & -.003 & .394 \\
\hline Debriefing feedback helpful to learning & $3.44 \pm .65$ & $3.71 \pm 0.5$ & 2.927 & $.004 *$ & .270 & .088 & .452 \\
\hline Adequate debriefing time to discuss performance & $3.32 \pm 0.67$ & $3.59 \pm 0.56$ & 2.734 & $.007 *$ & .267 & .074 & .460 \\
\hline Debriefing helped understand action rationale & $3.42 \pm 0.71$ & $3.58 \pm 0.52$ & 1.609 & .110 & .157 & -.036 & .350 \\
\hline Simulation helped develop stronger critical thinking & $3.44 \pm 0.65$ & $3.6 \pm 0.52$ & 1.660 & .099 & .153 & -.029 & .336 \\
\hline Simulation increased clinical judgments & $3.33 \pm 0.7$ & $3.59 \pm 0.56$ & 2.544 & $.012 *$ & .253 & .057 & .449 \\
\hline Simulation \& opportunity to participate decision making & $3.38 \pm 0.72$ & $3.55 \pm 0.54$ & 1.760 & .080 & .177 & -.022 & .375 \\
\hline Simulation \& improving bedside assessment & $3.44 \pm 0.62$ & $3.26 \pm 0.74$ & -1.676 & .096 & -.186 & -.404 & .033 \\
\hline Simulation \& managing complex clinical scenarios & $3.27 \pm 0.65$ & $3.45 \pm 0.69$ & 1.735 & .085 & .186 & -.026 & .398 \\
\hline Simulation improved prioritization & $3.34 \pm 0.65$ & $3.62 \pm 0.60$ & 2.841 & $.005^{*}$ & .283 & .086 & .479 \\
\hline Feel more prepared to care for critically ill & $3.13 \pm 0.77$ & $3.33 \pm 0.63$ & 1.811 & .072 & .203 & -.018 & .424 \\
\hline Simulation allowed me to set goals for the patient & $3.08 \pm 0.67$ & $3.43 \pm 0.60$ & 3.210 & $.002 *$ & .341 & .131 & .551 \\
\hline Simulation allowed me to experience interactive learning & $3.49 \pm 0.61$ & $3.33 \pm 0.60$ & -1.491 & .138 & -.152 & -.354 & .050 \\
\hline High Fidelity superior to traditional SimMan & $3.31 \pm 0.77$ & $3.52 \pm 0.59$ & 1.848 & .067 & .205 & -.014 & .424 \\
\hline Confident in clinical abilities & $3.23 \pm 0.64$ & $3.56 \pm 0.54$ & 3.597 & $.000 *$ & .338 & .152 & .523 \\
\hline Less anxious about caring for critically ill & $3.03 \pm 0.68$ & $3.05 \pm 0.81$ & .197 & .844 & .024 & -.220 & .269 \\
\hline Simulation allowed team work & $3.41 \pm 0.73$ & $3.29 \pm 0.72$ & -.982 & .328 & -.114 & -.344 & .116 \\
\hline Encouraged to take lead in making acute clinical decisions & $3.23 \pm 0.83$ & $3.25 \pm 0.72$ & .223 & .824 & .028 & -.216 & .271 \\
\hline Exploring professionalism \& bedside manner & $3.34 \pm 0.67$ & $3.82 \pm 0.42$ & 5.336 & $.000^{*}$ & .478 & .301 & .655 \\
\hline
\end{tabular}


3.2 Thematic analysis categories (Frequencies of participant responses for the content analysis categories)

In conducting the thematic analysis from the open-ended questions, two categories were identified (see Table 4). The categories were listed in order of frequency, from those with the greatest number of student participant responses to the fewest responses. The validity of the thematic analysis was supported through the inclusion of direct quotes from participants in the table below offering category descriptions. ${ }^{[22]}$ The two themes that emerged from the participants' responses about simulation impact were: (a) role selection during the simulation, and (b) the need for debriefing to be able to apply the knowledge and skills during simulation.

Table 4. Frequencies of participant responses for the content analysis categories

\begin{tabular}{|c|c|c|}
\hline Category & Number of Responses & Respondent Answers \\
\hline $\begin{array}{l}\text { Role selection during the } \\
\text { simulation }\end{array}$ & $44(60 \%)$ & $\begin{array}{l}\text { It was very useful teaching session playing the role of the patient. } \\
\text { Working in small group’s communication was good and students stayed in } \\
\text { their roles well. } \\
\text { Helps with working collaborative as a group. }\end{array}$ \\
\hline $\begin{array}{l}\text { Debriefing and how the } \\
\text { use of debriefing and } \\
\text { reflection takes into } \\
\text { account variations in } \\
\text { interpretations and the } \\
\text { individuality of the person } \\
\text { being assessed }\end{array}$ & 32 (37\%) & $\begin{array}{l}\text { Debriefing help me learn loads more and made me feel more comfortable } \\
\text { with the simulation. } \\
\text { The debriefing session was a good learning tool. } \\
\text { I felt supported during the debriefing session. } \\
\text { Initially it felt as though we were doing the lectures job for her but I now } \\
\text { know I have done it and feel more confident } \\
\text { myself. }\end{array}$ \\
\hline
\end{tabular}

\subsection{Concept 1: Role selection during the simulation}

Qualitative comments reflected some concern for more role selection during the simulation, how the use of role selection takes into consideration the variations in interpretations, and the individuality of the person being assessed. The recognized need of role selection for simulation are congruent with studies that report its positive benefits in creating situations that are safe for learning and that offer substantial benefits in team training. ${ }^{[23]}$ These studies confirm the increasing impact simulation has in patient care and improved outcomes in the clinical setting. ${ }^{[13]}$

\subsection{Concept 2: the need for debriefing}

The student participants described the need for debriefing and how the use of debriefing and reflection takes into account variations in understanding and the individuality of the person being assessed. It was readily apparent that the respondents could contribute to debriefing and feel more confident in their skillset and critical thinking.

\section{IMPLICATIONS AND RECOMMENDATIONS}

\subsection{Study limitations}

The study was conducted in a single institution using a convenience sample. The findings therefore may only be interpreted within that context. The sample size was small thus the results should be interpreted with caution and the findings should not be generalized to all nursing education students from this one study. In addition, the small sample size may explain the near significance results of some study variables that represent higher complex cognitive competencies including developing critical thinking, participation in decision making, improving bedside assessment, managing complex patients, and preparation to care for critically ill patients. Therefore, further quantitative and qualitative studies should be employed with larger samples to examine whether simulation is efficient in enhancing these important attributes. Adopting a mixed methods model through the use of interview or focus groups would also provide valuable insights into the students' experiences. Further research with students from different years in the nursing program and different institutions would allow a more thorough study of the simulation occurrences under examination.

\subsection{Change due to innovation, significance of project, fu- ture questions}

This study provides further evidence that supports the importance and utility of simulation in the education of nursing students. Results show that simulation was a valuable experience in advancing students' learning and clinical performance. Engagement in peer-led simulation was effective in increasing students' clinical judgement, prioritization, goal setting, confidence in clinical abilities, professionalism, and bedside manners. Simulation was also helpful in increasing students' satisfaction with debriefing and overall experience in the simulation lab. In addition, debriefing was very effective for reflective learning, as students discussed ob- 
stacles, barriers, and successful strategies related to patient assessment, communication with healthcare team members, problem solving, and critical thinking.

As such, this study presents important implications for the future. Pike and O'Donnell (2011) and others have found that simulation allows students to apply previous knowledge, increase competence through task or skill training, and develop higher-level skills related to communication, decision making, and teamwork. ${ }^{[24]}$ To date, we have continued to make changes in the simulation curriculum based on findings from this study. The QSEN-based rubrics serve as templates that can be used to introduce QSEN into other simulations in our curriculum. We believe these tools will assist in developing innovative methodologies for teaching QSEN content beyond the traditional classroom lecture format. By integrating the QSEN rubrics, it will permit the nursing faculty to share consensus and consistency in expected simulation learning outcomes. Since many of our clinical agencies partners use QSEN in staff development, we anticipate that QSEN-based tools such as this one may give useful indication of our graduates' readiness for new graduate residency training. The data generated thus far suggests that it is time to move for- ward and ask the questions of educators about identifying the critical components of what elements simulation facilitates in improving patient safety and contributing to successful transition to practice.

Future research may well include the intent to set up the analysis of quantitative data collected from our student surveys funding, a larger demographics, and using a reliable and validated tool.

\section{BIO STATEMENT}

Dr. Debra Wallace, DNP, RN, FNP-BC, serves as part time faculty in the School of Nursing at California State University of Northridge and mentors nursing students at Cal State University of Northridge and nurse practitioner students while working for Kaiser Permanente in Santa Clarita, CA.

Dr. Samira Moughrabi PhD, RN, APRN serves as an Assistant Professor in the School of Nursing at California State University of northridge.

\section{CONFLiCTS OF INTEREST Disclosure}

The authors declare that there is no conflict of interest statement.

\section{REFERENCES}

[1] Goodman JC, Villarreal P, Jones B. The social cost of adverse medical events, and what we can do about it. Health Affairs. 2011; 30(4): 590-595. PMid:21471477 http://dx.doi.org/10.1377/hltha ff. 2010.1256

[2] James JT. A new, evidence-based estimate of patient harms associated with hospital care. Journal of Patient Safety. 2013; 9(3): 122 128. PMid:23860193 http://dx.doi.org/10.1097/PTS.0b013 e3182948a69

[3] Kohn LT, Corrigan JM, Donaldson MS. To Err is Human: Building a Safer Health System. Institute of Medicine, Washington, D.C. National Academy Press; 2000.

[4] Baillie L, Curzio J. Students' and Facilitators' Perceptions of Simulation in Practice Learning. Nurse Education in Practice. 2009; 9(5): 297. PMid:18842463 http: //dx.doi.org/10.1016/j.nepr. 20 08.08 .007

[5] Tanner C. Changing times, evolving issues: The faculty shortage, accelerated programs, and simulation. Journal of Nursing Education. 2006; 45(3): 99-100. PMid:16629277

[6] Sideras S, McKenzie G, Noone J, et al. Making simulation come alive: Standardized patients in undergraduate nursing education. Nursing Education Perspectives. 2013; 34(6): 421-425. http: //dx.doi.o rg/10.5480/1536-5026-34.6.421

[7] Dyess SM, Sherman RO. The First Year of Practice: New Graduate Nurses' Transition and Learning Needs. Journal of Continuing Education in Nursing. 2009; 40(9): 403-410. PMid:19754027 http://dx.doi.org/10.3928/00220124-20090824-03

[8] Alinier G, Hunt B, Gordon R, et al. Effectiveness of Intermediatefidelity Simulation Training Technology in Undergraduate Nurs- ing Education. Journal of Advanced Nursing. 2006; 54(3): 359369. PMid:16629920 http://dx.doi.org/10.1111/j.1365-2 $648.2006 .03810 . \mathrm{x}$

[9] Issenberg SB, McGaghie WC, Petrusa ER, et al. Features and uses of high-fidelity medical simulations that lead to effective learning: A beme systematic review. Medical Teacher. 2005; 27(1): 1028. PMid:16147767 http://dx.doi.org/10.1080/014215905 00046924

[10] Gates GM, Parr BM, Hughes EJ. Enhancing Nursing Knowledge Using High-Fidelity Simulation. Journal of Nursing Education. 2012; 51(1): 189-209. http://dx.doi.org/10.3928/01484834-201 11116-01

[11] Gantt TL, Webb-Corbett R. Using Simulation to Teach Patient Safety behaviors in Undergraduate Nursing. Journal of Nursing Education. 2010; 49(1): 48-51. http://dx.doi .org/10.3928/01484834-2 0090918-10

[12] Jeffries P. A framework for designing, implementing, and evaluating simulations used as teaching strategies in nursing. Nursing Education Perspectives. 2005; 26(2): 96. PMid:15921126

[13] Bosek MS, Li S, Hicks FD. Working with standardized patients: A primer. International Journal of Nursing Education Scholarship. 2007; 4(1): e1-e12. PMid:17764442 http://dx.doi.org/10. 22 02/1548-923X.1437

[14] Waxman KT. The development of evidence-based clinical simulation scenarios: Guidelines for nurse educators. Journal of Nursing Education. 2010; 49(1): 29-35. PMid:19810672 http://dx.doi.org/1 $0.3928 / 01484834-20090916-07$

[15] Stevens DD, Levi AJ. Introduction to Rubrics: An assessment tool to save grading time, convey effective feedback, and promote student 
learning. Sterling, Virginia: Stylus Publishing LLC; 2005.

[16] Wallace D, Boller J. New nurse practitioner competencies: Skill development and reflective writing rubrics. Journal for Nurse Practitioners. 2014; 10(7): e13-e21. http://dx.doi.org/10.1016/j .nurpra.2014.04.018

[17] Cronenwett L, Sherwood G, Pohl J, et al. Quality and safety education for advanced nursing practice. Nursing Outlook. 2009; 57(6): 338-348. PMid:19942035 http://dx.doi.org/10.1016/j.out look. 2009.07.009

[18] Dolansky M, Moore S. Quality and safety education for nurses (qsen): The key is systems thinking. Online Journal of Issues in Nursing. 2013; 18(3): 71 .

[19] Sherwood G, Barnsteiner J. Quality and Safety in Nursing: A Competency Approach to Improving Outcomes [ebook]. Ames, IA: WileyBlackwell; 2012.
[20] Benner P. From Novice to Expert: Excellence and Power in Clinical Nursing Practice. Menlo Park, CA: Addison Wesley; 1984.

[21] Nolan J, Soar J, Zideman D, et al. European resuscitation council guidelines for resuscitation 2010 section 1. Executive summary. Resuscitation. 2010; 81(10): 1219-1276. PMid:20956052 http: //dx.doi.org/10.1016/j.resuscitation.2010.08.021

[22] Walker LO, Avant KC. Strategies for theory construction in nursing. Appleton-Century-Crofts; Norwalk, CT; 1995.

[23] Decker S, Sportsman S, Puetz L, et al. The evolution of simulation and its contribution to competency. The Journal of Continuing Education in Nursing. 2008; 39(2): 74-80. http://dx.doi .org/10 . 3928/00220124-20080201-06

[24] Pike T, O'Donnell V. The impact of clinical simulation on learner self-efficacy in pre-registration nursing education. Nurse Education Today. 2010; 30(5): 405-410. PMid:19883960 http://dx.doi.o $\mathrm{rg} / 10.1016 / \mathrm{j} . \mathrm{nedt} .2009 .09 .013$ 